Original

Article

\title{
Results of Emergency Coronary Artery Bypass Grafting for Acute Myocardial Infarction: Importance of Intraoperative and Postoperative Cardiac Medical Therapy
}

\author{
Akira Sezai, MD, PhD, Mitsumasa Hata, MD, PhD, Isamu Yoshitake, MD, PhD, \\ Haruka Kimura, MD, Kana Takahashi, MD, Hiroaki Hata, MD, PhD, and \\ Motomi Shiono, MD, PhD
}

\begin{abstract}
Background: The results of emergency coronary artery bypass grafting (CABG) for acute myocardial infarction (AMI) are less than satisfactory, and readmission for cardiac events is common.

Methods and Results: 105 patients underwent emergency CABG for AMI. We examined the long-term results of emergency CABG for AMI from the viewpoints of preoperative, intraoperative, and postoperative factors. The operative mortality rate was $11.4 \%$. Risk factors for early death were age $\geq 80$ years, shock, veno-arterial bypass, creatine kinase isoenzyme $\mathrm{Mb} \geq 100 \mathrm{U} / \mathrm{L}$, non-use of a left internal thoracic artery graft and an extracorporeal circulation time $\geq 120 \mathrm{~min}$. Risk factors for late cardiac events were ejection fraction $<40 \%$, non-use of human atrial natriuretic peptide (hANP) therapy, angiotensin II receptor blockers (ARB) and aldosterone blockers, and a 3-month postoperative brain natriuretic peptide level $\geq 200 \mathrm{pg} / \mathrm{ml}$.

Conclusions: Early results of this study are similar to those seen in previous reports, whereas late phase results yield some new and interesting findings. We suggest that intraoperative hANP, and postoperative aldosterone blocker and ARB, following CABG for AMI, will, through control of the renin-angiotensin-aldsterone system, inhibit left ventricular remodelling, reduce the extent of infarction, and improve cardiac function, yielding a favourable long-term prognosis.
\end{abstract}

Keywords: acute myocardial infarction, coronary artery bypass grafting, atrial natriuretic factor, angiotensin II receptor blocker, aldosterone blocker

\section{Introduction}

In recent years, operative results for emergency coronary artery bypass grafting (CABG) have been good, but

The Department of Cardiovascular Surgery, Department of Cardiology, Nihon University School of Medicine, Tokyo, Japan

Received: October 24, 2011; Accepted: December 19, 2011 Corresponding author: Akira Sezai, MD, PhD. The Department of Cardiovascular Surgery, Nihon University School of Medicine, 30-1 Oyaguchi-kamimachi, Itabashi-ku, Tokyo 173-8610, Japan Email: asezai.med@gmail.com (C)2012 The Editorial Committee of Annals of Thoracic and Cardiovascular Surgery. All rights reserved. it is performed for unstable angina in most cases, and CABG applied to acute myocardial infarction (AMI) has decreased. ${ }^{1)}$ Although, almost all AMI patients underwent percutaneous coronary intervention (PCI) as a first choice for early revascularization, emergency $\mathrm{CABG}$ is sometimes performed in patients with unsuccessful PCI, lesions of the main trunk of the left coronary artery, cardiogenic shock and multi vessel disease. The early mortality rate of CABG for AMI is reported to be between $8.2 \%$ and $42.6 \% .^{2-7)}$ In addition, many patients show delayed cardiac events and cardiac death. In the SHOCK trial for AMI patients with cardiogenic shock, White et al. reported that patients treated with $\mathrm{CABG}$ had a greater 
prevalence of diabetes and more severe coronary disease than did those treated with PCI. However, survival rates were similar. ${ }^{5)}$ Emergency CABG is an important component of an optimal treatment strategy.

Previously, we have investigated cases of emergency CABG for unstable angina and reported good results including operative mortality of $1.9 \%$, five-year survival rate of $89.2 \%$ and 10 -year survival rate of $84.1 \%$. In our investigation, risk factors for postoperative cardiac events were female sex, chronic renal failure, hemodialysis, nonuse of human atrial natriuretic peptide (hANP), nonuse of angiotensin II receptor blockers (ARB) and aldosterone blockers, and 3-month postoperative brain natriuretic peptide (BNP) level $>200 \mathrm{pg} / \mathrm{ml}^{8}{ }^{8)}$ After AMI, operative mortality was not only higher than that for unstable angina, but also, there was a cardiac functional decrease, due to extensive residual infarction and onset of problems with arrhythmia; long-term results were not good and results have not been satisfactory so far. Most published studies of emergency CABG for AMI only provide shortterm results, and reports of long-term outcomes are rare. Therefore, we examined long-term outcomes of emergency CABG for AMI in the present retrospective study.

\section{Patients and Methods}

105 patients underwent emergency CABG for AMI at Nihon University Itabashi Hospital between 1 May 1996 and 31 December 2009. Indications for surgery were infarction of the left anterior descending arterial territory within 24 hours of onset. In general, all procedures were performed under cardiopulmonary bypass, and a left internal thoracic artery (LITA) graft was used for the left anterior descending artery (but not if the LITA was unsuitable for harvesting, e.g. due to unstable hemodynamics), and a radial artery and/or saphenous vein graft was used for other sites in our institute. The indications for emergency CABG were decided according to the Japanese Circulation Society Guidelines (http://www.j-circ.or.jp/guideline/pdf/ JCS2007_yamaguchi_h.pdf). Treatment plans were devised in consultation with cardiologists. In this study, we defined myocardial infarction with ST elevation (STEMI) or non-STEMI with electrocardiograph changes and a preoperative creatine kinase isoenzyme $\mathrm{Mb}$ (CK-MB) level twice the upper limit of the normal range as AMI. Indications for V-A bypass were as follows: 1) patients with cardiogenic shock with assisted circulation by IABP (intraaortic balloon pump) and 2) patients with cardiac arrest. IABP indications were 1) patients with cardiogenic shock,
2) patients with no improvement in ST changes in ECGs and in left main coronary artery lesions with unstable hemodynamics, 3) patients with severe triple vessel disease with unstable hemodynamics, 4) patients with refractory arrhythmia, and 5) patients with unsuccessful PCI.

The preoperative factors examined were age $\geq 80$ years, gender, shock, lesions of the main trunk of the left coronary artery, CK-MB level $\geq 100 \mathrm{U} / \mathrm{L}$, ejection fraction $<40 \%$, intra-aortic balloon pump, veno-arterial bypass, diabetes mellitus, hypertension, dyslipidemia, obesity, smoking, chronic renal failure, hemodialysis, cerebrovascular disease, a EuroSCORE $\geq 10$, and a BNP level $\geq 200 \mathrm{pg} / \mathrm{ml}$. Intraoperative factors examined were aortic cross clamping time $\geq 60 \mathrm{~min}$, extracorporeal circulation time $\geq 120 \mathrm{~min}$, nonuse of the left internal thoracic artery, and intraoperative commencement of hANP therapy. The postoperative factors investigated were postoperative administration of angiotensin II receptor blocker (ARB), aldosterone blockers, angiotensin-converting enzyme inhibitors, $\beta$-blockers, $\mathrm{Ca}$ antagonists, and statins, and 3-month postoperative BNP level $\geq 200 \mathrm{pg} / \mathrm{ml}$. We measured BNP and aldosterone levels immediately prior to surgery and 3 months postoperatively. We examined early results and cardiac events (defined as hospitalization with heart failure and arrhythmia, or ischemic heart disease requiring treatment) in patients who were discharged from hospital after surgery. This was a retrospective study with a $100 \%$ follow-up rate and a mean follow-up period of $6.53 \pm 3.58$ years $(1.3-14.8$ years). Approval for this study was received from the Ethics Committee of Nihon University Itabashi Hospital. Details of the study were explained to each patient and/or the family, and informed consent was obtained.

All patients were continuously administered aspirin ( $81-100 \mathrm{mg} /$ day) and isosorbide dinitrate $(40 \mathrm{mg} /$ day $)$ postoperatively. A calcium antagonist was administered to patients who had undergone radial arterial grafting, to prevent vasospasm. Treatment with ARB, angiotensin-converting enzyme inhibitors, $\beta$-blocker, and aldosterone blockers was given at the discretion of the attending physician.

Results are given as the mean \pm SD. For statistical analysis, univariate logistical regression analysis of the preoperative, intraoperative, and postoperative factors was performed. Variables showing significance were then subjected to multivariate analysis. The overall mortality rate, cardiovascular mortality rate, and postoperative cardiovascular event-free rate were determined by the Kaplan-Meier method. Student's t-test and Fisher's exact test were used for other statistical analyses. A probability (p) value of $<0.05$ was considered to indicate statistical significance. 
Table 1 Preoperative patient profile

\begin{tabular}{lc}
\hline Characteristics & $(\mathrm{n}=105)$ \\
\hline Age (years) & $66.9 \pm 9.6(40-85)$ \\
$\geq 80$ years & $8(7.6 \%)$ \\
Gender (male: female) & $80: 25$ \\
BSA (m2) & $1.63 \pm 0.15(1.21-2.02)$ \\
Preoperative factors & $19(18.1 \%)$ \\
Shock & 7 \\
Veno-arterial bypass & 17 \\
IABP & $60(57.1 \%)$ \\
Left main trunk lesion & $11.4 \pm 2.0(9-17)$ \\
EuroSCORE & $81(77.1 \%)$ \\
EuroSCORE $\geq 10$ & $49(46.7 \%)$ \\
Diabetes mellitus & $79(75.2 \%)$ \\
Hypertension & $53(50.5 \%)$ \\
Dyslipidemia & $16(15.2 \%)$ \\
Obesity & $51(48.6 \%)$ \\
Smoking & $24(22.9 \%)$ \\
Chronic renal failure & $8(7.6 \%)$ \\
Cerebral infarction & $11(10.5 \%)$ \\
Hemodialysis & $27(25.7 \%)$ \\
Ejection fraction $<40 \%$ & $70(66.7 \%)$ \\
IABP & $7(6.7 \%)$ \\
Veno-arterial bypass & $16(15.2 \%)$ \\
CK-MB $\geq 100$ & $35(34.7 \%)$ \\
BNP $\geq 200$ pg/ml & $258.9 \pm 355.6(12-2350)$ \\
BNP (pg/ml) & $3 \pm 3.58(1.3-14.8)$ \\
Average follow-up (years) & \\
\hline BSA: body surface area & \\
\hline &
\end{tabular}

BSA: body surface area; IABP: intra-aortic balloon pumping; BNP: brain natriuretic peptide

\section{Results}

Preoperative background and intraoperative and postoperative factors of the 105 patients are summarized in Table 1 and Table 2. CABG is basically on-pump in our hospital (especially AMI patients with a possibility of unstable hemodynamics). In this study, off-pump CABG was used in two patients, but both patients had a porcelain aorta as a complication. Off-pump was selected in patients with bypass to LAD or RCA\#3. The average numbers of grafts was $3.1 \pm 0.9$. The arterial graft used instead of LITA for LAD was RITA in one case and radial artery in another case; others were all saphenous vein grafts.

The operative mortality rate was $11.4 \%(n=12)$. The cause of death was low output syndrome in 5 cases, heart failure, pneumonia and mediastinitis, in 2 cases each, and cardiac rupture in 1 . Five out of seven patients requiring V-A bypass assist and 11 out of 70 patients requiring IABP assist preoperatively showed early mortality.

There were 9 late deaths after discharge, with the cause being heart failure, arrhythmia, cerebral infarction
Table 2 Intraoperative and postoperative data

\begin{tabular}{|c|c|}
\hline & $(\mathrm{n}=105)$ \\
\hline \multicolumn{2}{|l|}{ Intraoperative factors } \\
\hline LITA graft & $86(81.9 \%)$ \\
\hline Numbers of graft & $3.1 \pm 0.9$ \\
\hline Conventional CABG & $102(97.1 \%)$ \\
\hline On pump beating $\mathrm{CABG}$ & $1(1.0 \%)$ \\
\hline Off pump CABG & $2(1.9 \%)$ \\
\hline $\operatorname{ACCT}(\min )$ & $49.5 \pm 24.9(0-102)$ \\
\hline $\mathrm{ACCT} \geq 90 \mathrm{~min}$ & $7(6.7 \%)$ \\
\hline $\operatorname{ECCT~(min)~}$ & $113.4 \pm 39.6(0-195)$ \\
\hline $\mathrm{ECCT} \geq 120 \mathrm{~min}$ & $37(35.2 \%)$ \\
\hline hANP infusion & $49(46.7 \%)$ \\
\hline \multicolumn{2}{|l|}{ Postoperative factors } \\
\hline Aspirin & $94(100 \%)$ \\
\hline Isosorbide dinitrate & $93(98.9 \%)$ \\
\hline $\mathrm{ARB}$ & $40(42.6 \%)$ \\
\hline ACE-I & $8(8.5 \%)$ \\
\hline$\beta$-blockers & $23(24.5 \%)$ \\
\hline Aldosterone blocker & $50(53.2 \%)$ \\
\hline Calcium antagonist & $57(60.6 \%)$ \\
\hline Statin & $72(68.6 \%)$ \\
\hline Strong statin & $45(60.0 \%)$ \\
\hline Standard statin & $10(13.9 \%)$ \\
\hline Standard statin strong statin & $17(23.6 \%)$ \\
\hline $\mathrm{BNP}$ (3 months, pg/ml) & $177.7 \pm 262.1(10-2000)$ \\
\hline $\mathrm{BNP}(3$ months $) \geq 200 \mathrm{pg} / \mathrm{ml}$ & $27(29.3 \%)$ \\
\hline
\end{tabular}

LITA: left internal thoracic artery; ACCT: aortic cross clamping time; ECCT: extracorporeal circulation time; hANP: human atrial natriuretic peptide; ARB: angiotensin II receptor blocker; ACE-I: angiotensin-converting enzyme inhibitor; BNP: brain natriuretic peptide

and malignancy, in 2 cases each, and acute renal failure in 1 . The postoperative 1-year survival rate was $86.7 \%$, the 5-year survival rate was $83.1 \%$, and the 10 -year survival rate was $71.7 \%$ (Fig. 1). The postoperative cardiac event-free rate was $86.5 \%$ at 1 year, $71.5 \%$ at 5 years, and $54.4 \%$ at 10 years (Fig. 2).

Analysis of early, all-cause death revealed the following risk factors (Table 3): Univariate analysis confirmed that age $\geq 80$ years $(p=0.0077)$, shock $(p<0.0001)$, veno-arterial bypass ( $\mathrm{p}=0.0002), \mathrm{CK}-\mathrm{MB} \geq 100 \mathrm{U} / \mathrm{L}(\mathrm{p}<0.0001)$, LITA $(\mathrm{p}=0.0052)$, and extracorporeal circulating time $\geq 120$ min ( $p=0.0122)$ were risk factors. Multivariate analysis confirmed that veno-arterial bypass $(p=0.0492)$ and CK-MB $\geq 100 \mathrm{U} / \mathrm{L}$ ( $\mathrm{p}=0.0243$ ) were risk factors.

Analysis of late cardiac events revealed the following risk factors (Table 4): Univariate analysis-confirmed ejection fraction $<40 \%(\mathrm{p}=0.0362)$, hANP therapy $(\mathrm{p}=$ $0.0382), \operatorname{ARB}(\mathrm{p}=0.0187)$, aldosterone blocker $(\mathrm{p}=$ 0.0183 ), and a 3 -month postoperative BNP level $\geq 200$ $\mathrm{pg} / \mathrm{ml}(\mathrm{p}=0.0002)$. 


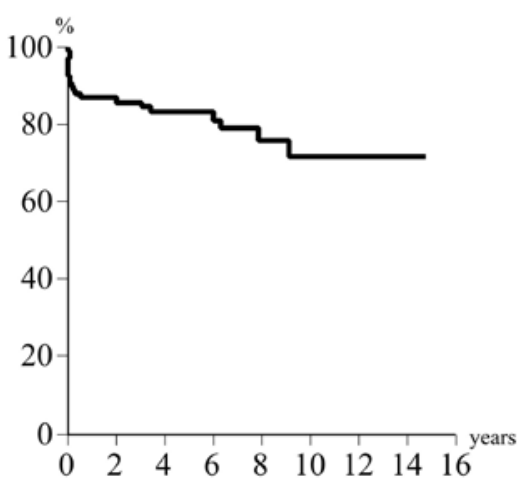

Fig. 1 Survival rates for all-cause death.

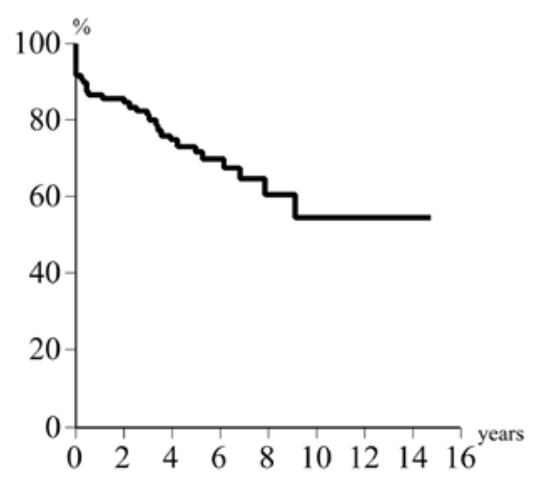

Fig. 2 Postoperative cardiac event-free rates.

Table 3 Intraoperative and postoperative factors and early all cause death

\begin{tabular}{|c|c|c|c|c|}
\hline & \multicolumn{2}{|c|}{ Univariate } & \multicolumn{2}{|c|}{ Multivariate } \\
\hline & Odds ratio $(95 \% \mathrm{CI})$ & $\mathrm{p}$ value & Odds ratio $(95 \% \mathrm{CI})$ & $\mathrm{p}$ value \\
\hline \multicolumn{5}{|l|}{ Preoperative factors } \\
\hline Age $\geq 80$ years & 7.25 (1.69-31.2) & 0.0077 & $5.07(0.58-44.4)$ & 0.1424 \\
\hline Gender male & $0.36(0.10-1.26)$ & 0.1094 & & \\
\hline EuroSCORE $\geq 10$ & $3.83(0.47-31.2)$ & 0.2103 & & \\
\hline Diabetes mellitus & $1.16(0.35-3.87)$ & 0.8059 & & \\
\hline Hypertension & $0.41(0.12-1.42)$ & 0.1590 & & \\
\hline Dyslipidaemia & $2.13(0.60-7.58)$ & 0.2413 & & \\
\hline Obesity & $2.05(0.49-8.59)$ & 0.3255 & & \\
\hline Smoking & $0.73(0.22-2.47)$ & 0.6121 & & \\
\hline Cerebrovascular disease & $2.90(0.52-16.3)$ & 0.2274 & & \\
\hline Chronic renal failure & $1.83(0.50-6.69)$ & 0.3637 & & \\
\hline Haemodialysis & $1.83(0.80-15.8)$ & 0.0972 & & \\
\hline Left main tract lesion & $1.58(0.44-5.61)$ & 0.4815 & & \\
\hline Shock & $14.9(3.84-57.8)$ & $<0.0001$ & $4.85(0.65-36.0)$ & 0.1224 \\
\hline IABP & $6.34(0.78-51.3)$ & 0.0833 & & \\
\hline V-A bypass & $32.5(5.31-198.8)$ & 0.0002 & $11.4(0.83-158.5)$ & 0.0492 \\
\hline CK-MB $\geq 100$ U/L & $21.3(5.23-86.4)$ & $<0.0001$ & 8.85 (1.33-59.0) & 0.0243 \\
\hline Ejection fraction $<40 \%$ & $1.52(0.42-5.53)$ & 0.5233 & & \\
\hline $\mathrm{BNP} \geq 200 \mathrm{pg} / \mathrm{dl}$ & $1.36(0.40-4.64)$ & 0.6213 & & \\
\hline \multicolumn{5}{|l|}{ Intraoperative factors } \\
\hline LITA & $0.16(0.05-0.53)$ & 0.0052 & $0.38(0.04-3.30)$ & 0.3803 \\
\hline $\mathrm{ECCT} \geq 120 \mathrm{~min}$ & $5.15(1.43-18.6)$ & 0.0122 & $4.13(0.66-25.7)$ & 0.0650 \\
\hline hANP therapy & $0.53(0.15-1.89)$ & 0.3309 & & \\
\hline
\end{tabular}

BNP: brain natriuretic peptide; IABP: intra aortic balloon pumping; V-A: veno-arterial; CK-MB: creatine kinase isoenzyme $\mathrm{Mb}$; LITA: left internal thoracic artery; ECCT: extracorporeal circulation time; hANP: human atrial natriuretic peptide

Analysis of the relation between the preoperative BNP level and early death revealed no statistically significant difference between the BNP level of survivors (262.4 \pm $369.7 \mathrm{pg} / \mathrm{ml})$ versus non-survivors $(203.6 \pm 88.4 \mathrm{pg} / \mathrm{ml})$ $(\mathrm{p}=0.5856)$ (Fig. 3).

Analysis of the relation between the preoperative BNP level and late cardiac events revealed no significant difference between the BNP level of $297.1 \pm 281.2 \mathrm{pg} / \mathrm{ml}$ in the cardiac event group with that of $254.1 \pm 389.1 \mathrm{pg} / \mathrm{ml}$ in the event-free group $(p=0.6603)($ Fig. 3).
As shown in Fig. 3, however, the 3-month postoperative BNP level was significantly lower in the event-free group $(144.2 \pm 185.4 \mathrm{pg} / \mathrm{ml})$ than in the cardiac event group $(318.9 \pm 437.0 \mathrm{pg} / \mathrm{ml})(\mathrm{p}=0.0101)$.

\section{Discussion}

In this study, we identified age $\geq 80$ years, shock, venoarterial bypass, CK-MB $\geq 100$ U/L, LITA, and extracorporeal circulating time $\geq 120 \mathrm{~min}$ as predictors of a poor early 
Table 4 Preoperative, intraoperative and postoperative factors and late phase cardiac events

\begin{tabular}{|c|c|c|c|c|}
\hline & \multicolumn{2}{|c|}{ Univariate } & \multicolumn{2}{|c|}{ Multivariate } \\
\hline & Odds ratio $(95 \% \mathrm{CI})$ & $\mathrm{p}$ value & Odds ratio $(95 \% \mathrm{CI})$ & $\mathrm{p}$ value \\
\hline \multicolumn{5}{|l|}{ Preoperative factors } \\
\hline Age $\geq 80$ years & $0.60(0.08-2.11)$ & 0.7793 & & \\
\hline Gender male & $0.88(0.25-3.05)$ & 0.8338 & & \\
\hline EuroSCORE $\geq 10$ & $0.88(0.28-2.80)$ & 0.8351 & & \\
\hline Diabetes mellitus & $1.59(0.57-4.48)$ & 0.3795 & & \\
\hline Hypertension & $2.71(0.57-12.9)$ & 0.2095 & & \\
\hline Dyslipidaemia & $1.08(0.39-3.03)$ & 0.8788 & & \\
\hline Obesity & $0.73(0.15-3.61)$ & 0.6970 & & \\
\hline Smoking & $1.35(0.48-3.81)$ & 0.5656 & & \\
\hline Cerebrovascular disease & $1.60(0.59-5.14)$ & 0.8793 & & \\
\hline Chronic renal failure & $1.05(0.31-3.65)$ & 0.9343 & & \\
\hline Haemodialysis & $2.80(0.60-13.0)$ & 0.1890 & & \\
\hline Left main tract lesion & $3.41(1.03-11.3)$ & 0.0752 & & \\
\hline Shock & $4.42(1.17-16.7)$ & 0.0680 & & \\
\hline IABP & $1.64(0.53-5.08)$ & 0.3919 & & \\
\hline V-A bypass & $4.35(0.26-73.2)$ & 0.3069 & & \\
\hline $\mathrm{CK}-\mathrm{MB} \geq 100 \mathrm{U} / \mathrm{L}$ & $1.44(0.27-7.79)$ & 0.6239 & & \\
\hline Ejection fraction $<40 \%$ & $3.20(1.08-9.50)$ & 0.0362 & $2.09(0.45-9.59)$ & 0.3442 \\
\hline $\mathrm{BNP} \geq 200 \mathrm{pg} / \mathrm{dl}$ & $1.00(0.34-2.98)$ & $>0.999$ & & \\
\hline \multicolumn{5}{|l|}{ Intraoperative factors } \\
\hline LITA not used & $1.38(0.28-6.83)$ & 0.6970 & & \\
\hline $\mathrm{ECCT} \geq 120 \mathrm{~min}$ & $0.69(0.20-2.33)$ & 0.5476 & & \\
\hline hANP therapy & $0.34(0.11-1.04)$ & 0.0382 & $0.98(0.16-3.98)$ & 0.4305 \\
\hline \multicolumn{5}{|l|}{ Postoperative factors } \\
\hline $\mathrm{ARB}$ & $0.21(0.06-0.77)$ & 0.0187 & $0.43(0.08-2.26)$ & 0.3212 \\
\hline ACE-I & $1.44(0.27-7.79)$ & 0.6739 & & \\
\hline$\beta$ blocker & $0.34(0.07-1.63)$ & 0.1787 & & \\
\hline Aldosterone blocker & $0.26(0.09-0.79)$ & 0.0183 & $0.42(0.09-1.92)$ & 0.2613 \\
\hline $\mathrm{Ca}$ antagonist & $0.99(0.35-2.85)$ & 0.9861 & & \\
\hline Statin & $0.66(0.24-1.87)$ & 0.4371 & & \\
\hline BNP (3 month) $\geq 200 \mathrm{pg} / \mathrm{dl}$ & $9.59(3.00-30.9)$ & 0.0002 & $3.17(0.70-14.4)$ & 0.1342 \\
\hline
\end{tabular}

BNP: brain natriuretic peptide; hANP: human atrial natriuretic peptide; CK-MB: creatine kinase isoenzyme Mb; IABP: intra aortic balloon pumping; V-A: veno-arterial; LITA: left internal thoracic artery; ECCT: extracorporeal circulation time; ARB: angiotensin II receptor blocker; ACE-I: angiotensin-converting enzyme inhibitor

phase postoperative outcome. The veno-arterial bypass, CK-MB $\geq 100 \mathrm{U} / \mathrm{L}$, and LITA factors were also present in all patients with shock. Past studies have also identified shock as a strong risk factor, with unfavourable early phase postoperative results in patients with AMI or preoperative shock. Four out of 7 patients had a poor prognosis after the $\mathrm{V}-\mathrm{A}$ bypass because cardiac massage was performed as the patients were brought into the operating room. There was hemodynamic destruction of cells because of extensive, preoperative myocardial infarction.

In the SHOCK trial conducted with 128 patients with AMI complicated by cardiogenic shock, despite a higher proportion of patients with diabetes mellitus and worse coronary disease, survival rates were the same at 30 days and at 1 year in the CABG group and the PCI group. The reported survival rates were extremely poor, however,
$57.4 \%$ at 30 days and $46.8 \%$ at 1 year. ${ }^{5)}$ Thielmann et al. studied 254 patients who underwent emergency CABG surgery for acute coronary syndrome, finding that preoperative troponin I levels and age were the strongest predictors of early phase mortality and cardiac events. ${ }^{9)}$ In this study, we did not measure troponin I levels in all patients and were unable to perform any analyses, but we did identify a CK-MB level $\geq 100 \mathrm{U} / \mathrm{L}$ as a risk factor. The challenge for the future is how to improve outcomes in patients with extensive myocardial infarctions, whether by PCI or CABG.

We identified ejection fraction $<40 \%$, hANP therapy, ARB, aldosterone blocker, and a 3 month postoperative BNP level $\geq 200 \mathrm{pg} / \mathrm{ml}$ as risk factors for late phase cardiac events. From these results, cardiac events after discharge were decreased by hANP therapy as perioperative management and by ARB and aldosterone blockers inhibit 


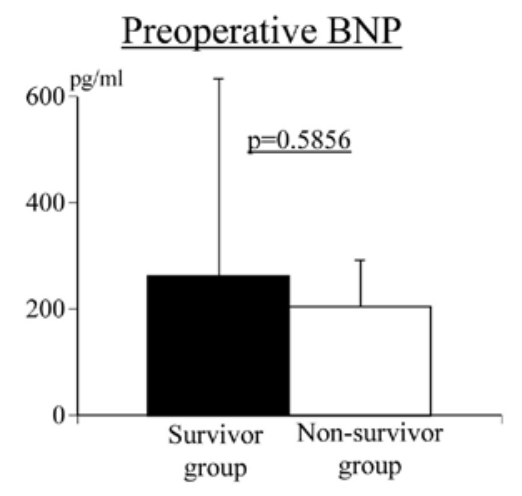

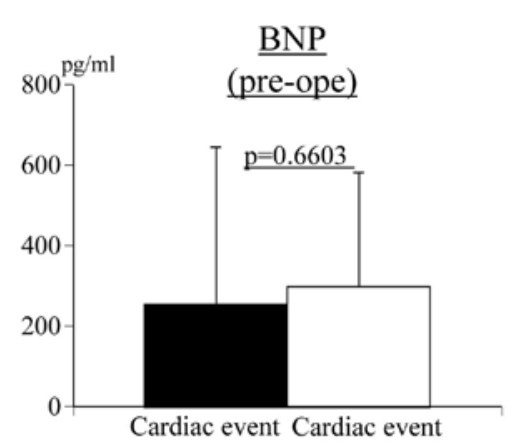

$(-)$

$(+)$

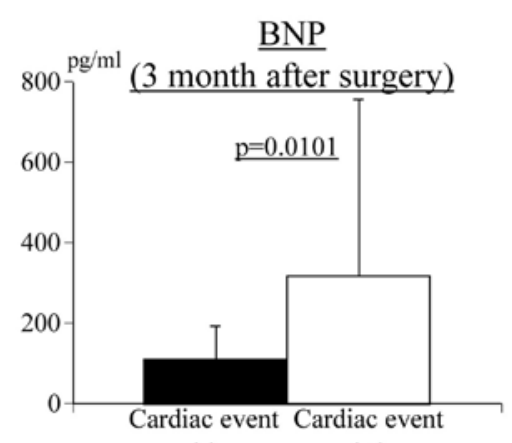

$(-)$

$(+)$

Fig. 3 Relation between the preoperative brain natriuretic peptide levels and early death and relation between the preoperative or 3 month postoperative brain natriuretic peptide level and cardiac events. BNP: brain natriuretic peptide

postoperative increases in aldosterone and prevent left ventricular remodeling after AMI as postoperative medical management. From the above results, the strongest predictors of early phase results are factors associated with shock, whereas the strongest predictors of late phase results are factors associated with postoperative heart failure and left ventricular remodelling. The early phase results for this study are similar to those seen in previous reports, whereas the late phase results yield some new and interesting findings.

The level of serum BNP is now an important factor in evaluating prognosis of patients. From this study, BNP exceeding $200 \mathrm{pg} / \mathrm{ml}$ at 3 months postoperatively was found to be a risk factor for postoperative cardiac events. Therefore, patients with BNP exceeding $200 \mathrm{pg} / \mathrm{ml}$ postoperatively have to be adequately managed by measures such as strengthening medical therapy within 3 months postoperatively. Several reports on preoperative and perioperative BNP changes have been published, but almost none of the reports have been on postoperative follow-up cases and few patients usually show normalization of postoperative BNP values. Therefore, the level above which elevated BNP lev- els become a risk factor is not clear. In a study performed on outpatients after heart failure in the field of cardiology in the past, it was reported that BNP of $190 \mathrm{pg} / \mathrm{ml}$ at 6 months after discharge was the cut-off value for readmission. ${ }^{10)}$ The present study did not include any patients with heart failure, but because of the effects of left ventricular remodeling after acute myocardial infarctions and the effects of adhesion, etc. after cardiac surgery, the presence or absence of cardiac events in patients with BNP levels of $200 \mathrm{pg} / \mathrm{ml}$ or higher at 3 months postoperatively was examined in this study. However, it will be necessary to collect more patients in the future, study changes in follow-up BNP levels after discharge and verify the cut-off value of BNP for the onset of evens after cardiac surgery.

Research on medical therapy after AMI included many studies after PCI, but few studies after CABG. hANP is only used in Japan at present, while BNP (Nesiritide) has not been approved in Japan, but is used in Western countries. We previously performed a randomized controlled trial known as the Nihon University Working Group Study of low-dose hANP infusion therapy during cardiac surgery (NU-HIT trial), in which hANP was administered periop- 
eratively for cardiac and renal protection. Because hANP inhibits the renin-angiotensin-aldsterone system and has a potent natriuretic effect, we have found that it can compensate for the adverse effects of cardiopulmonary bypass and can inhibit reperfusion injury, left ventricular remodeling, postoperative arrhythmia and renal dysfunction. ${ }^{11-16)}$ In an experiment study, cyclic guanosine monophosphate was increased by the administration of hANP, and myocardial protective effects were reported. ${ }^{17,18)}$ Recently, continuous intravenous administration of hANP or BNP have been performed in cardiac surgery worldwide, its cardiac and reno-protective effects have been reported. ${ }^{19,20)}$ The only large-scale studies of hANP performed so far are a multicenter study of hANP administration after reperfusion therapy in patients with acute myocardial infarction (JWIND study). In the J-WIND study, the hANP group showed a significantly smaller infarct size, greater improvement of cardiac function, and significantly fewer cases of cardiac death and heart failure than the placebo group. ${ }^{21)}$ From the results of this study, we can see that cardiac events were prevented through suppression of aldosterone levels, by hANP in the early phase, and by ARB and aldosterone blocker in the late phase. Aldosterone is a hormone that is strongly involved in left ventricular remodelling, and can, therefore, be utilised to prevent postoperative cardiac events.

As for an aldosterone blocker, the EPHESUS trial, eplerenone, in the treatment of AMI associated with left ventricular dysfunction, reported significantly lower cardiovascular mortality in the aldosterone blocker group than in the control group. ${ }^{22)}$ In the experimental study, Fraccarollo et al. reported that the aldosterone blocker improved left ventricular remodeling with left ventricular dysfunction after AMI and combination therapy with an angiotensin-converting enzyme inhibitor recognized prevention of left ventricular fibrosis, cardiac hypertrophy, and molecular alterations. ${ }^{23)}$

A number of studies have confirmed the efficacy of $\mathrm{ARB}$ and angiotensin-converting enzyme inhibitor in the treatment after AMI. In the SAVE trial using an angiotensin-converting enzyme inhibitor (captopril), preventive effects on MI recurrence were reported. ${ }^{24)}$ In the VALIANT trial using the ARB valsartan and the OPTIMAAL trial using losartan, it was clear that about the same allcause mortality and effects on cardiac events were obtained as with the angiotensin-converting enzyme inhibitor (captopril). ${ }^{25,26)}$ Pitt et al. reported that the EPHESUS trial recommended concomitant therapy with an aldosterone blocker, angiotensin-converting enzyme inhibitor or ARB and a beta-blocker as medical therapy after AMI. ${ }^{27)}$ In the ACC/AHA guidelines, renin-angiotensin inhibitors (angiotensin-converting enzyme inhibitor, $\mathrm{ARB}$ ) and aldosterone blockers are recommended as secondary preventive agents. These are important drugs in the prevention of left ventricular remodeling and cardiac events. ${ }^{28)}$ However, few studies have examined oral medications following CABG for AMI. There are no reports to date of ARB and aldosterone blocker as postoperative cardiac medical therapy. Okrainec et al. conducted a review of randomized controlled trial, finding that aspirin and statin reduce postoperative cardiac events, and recommended their use. Short-term calcium antagonist therapy was useful in patients who underwent radial arterial grafting, although the long-term benefits were unclear. They found only one randomized controlled trial had been conducted, respectively, with beta blocker and angiotensin-converting enzyme inhibitor, so their effectiveness was unknown, and further studies are required. ${ }^{29)}$ Filion et al. also conducted a review of a randomized controlled trialand found only 4 studies of angiotensin-converting enzyme inhibitor, including one randomized controlled trial. The lack of long-term follow-up meant that the efficacy of angiotensin-converting enzyme inhibitor was unconfirmed. They found several small-scale studies of beta blocker, including 3 randomized controlled trials, and although beta blocker was reported to reduce postoperative atrial fibrillation, the evidence was unconvincing. ${ }^{30}$ )

Hypotension is a known side effect of carperitide, but if the dose is as low as $0.02 \mu \mathrm{g} / \mathrm{kg} / \mathrm{min}$, there is no effect on blood pressure. It was clear from our previous research. ${ }^{11)}$ The side effects of aldosterone blockers are gynecomastia and hyperkalemia. Gynecomastia was observed with spironolactone but not with eplerenone. Hyperkalemia was found in several patients, but we did not experience patients with potassium values exceeding 6.0 when we reduced the aldosterone blocker dose or used drugs to lower potassium values. The problem with ARBs is that they cause aldosterone breakthrough on long-term administration. This leads to left ventricular remodeling and affects survival prognosis. In patients experiencing aldosterone breakthrough after administration of ARB, it can be suppressed by the addition of administration of aldosterone blockers. In our hospital, a randomized controlled trial on medical treatment during and after the operation is now underway. Since all of the results have not been obtained, conclusions cannot be drawn. However, from the results of retrospective this study, treatment with carperitide is used during surgery at present for AMI. After surgery, aspirin, isosorbide dinitrate, and statins are 
used, as well as aldosterone blockers, beta-blockers, and ARB for prevention of left ventricular remodeling.

We examined not only early results, but also long-term results, following emergency CABG for AMI. Our results show poor early phase results, and also unsatisfactory longterm outcomes, in patients with AMI complicated by shock. This suggests that we need to reconsider, in consultation with our cardiologist colleagues, whether $\mathrm{CABG}$ surgery or PCI is indicated in patients with AMI complicated by shock, or a CK-MB level $\geq 100 \mathrm{U} / \mathrm{L}$. We have shown that intraoperative hANP, and postoperative aldosterone blocker and ARB, will through control of the reninangiotensin-aldsterone system inhibit left ventricular remodelling, reduce the extent of infarction, and improve cardiac function, yielding a favourable long-term prognosis. The best results require not just good surgical techniques, but also intraoperative and postoperative cardiac medical therapy with the long-term outcome in mind.

\section{Limitations}

The subjects of this study were AMI patients, but both STEMI and non-STEMI cases were examined. The prognosis would have been different if these two types had been distinguished in the study. Since an adequate study was impossible because of the small number of patients, STEMI and non-STEMI cases were examined together. In the future, we hope to accumulate more patients and distinguish between STEMI and non-STEMI cases.

This was a retrospective study, and assessments by randomized control trials are important to indicate the efficacy of the drug more clearly. We are performing randomized control trials on hANP (trial number: UMIN000001654), ARB (UMIN000001463) and aldosterone blocker (UMIN000001467) with cardiac surgery patients as subjects and will report the results when the targeted number of patients are reached in the future. From these results, the efficacy of postoperative drug therapy in emergency CABG should be clearer.

\section{Funding Sources}

This study was conducted with support of a Research Grant from the Japanese Ministry of Education, Culture, Sports, Science and Technology (No.21591805); Takeda Science Foundation, a Nihon University Medical School Alumni 60th Anniversary Medical Research Grant; and a Nihon University Medical School Foundation 50th Anniversary Medical Research Grant.

\section{References}

1) Nallamothu BK, Young J, Gurm HS, et al. Recent trends in hospital utilization for acute myocardial infarction and coronary revascularization in the United States. Am J Cardiol 2007; 99: 749-53.

2) Weiss ES, Chang DD, Joyce DL, et al. Optimal timing of coronary artery bypass after acute myocardial infarction: A review of California discharge data. J Thoracic CardiovascSurg 2008; 135: 503-11.

3) Saleh SS, Hannan EL, Ting L. A multistate comparison of patient characteristics, outcomes, and treatment practices in acute myocardial infarction. Am J Cardiol 2005; 96: 1190-6.

4) Miyahara K, Matsuura A, Takemura H, et al. Onpump beating-heart coronary artery bypass grafting after acute myocardial infarction has lower mortality and morbidity. J Thorac Cardiovasc Surg 2008; 135: 521-6.

5) White HD, Assmann SF, Sanborn TA, et al. Comparison of percutaneous coronary intervention and coronary artery bypass grafting after acute myocardial infarction complication by cardiogenic shock; results from the should we emergently revascularize occluded coronaries for cardiogenic shock (SHOCK) trial. Circulation 2005; 112: 1992-2001.

6) Apolito RA, Greenberg MA, Menegus MA, et al. Impact of the New York state cardiac surgery and percutaneous coronary intervention reporting system on the management of patients with acute myocardial infarction complicated by cardiogenic shock. Am Heart J 2008; 155: 267-73.

7) Osawa H, Fujimatsu T. Emergency coronary artery bypass grafting for left main shock syndrome. Ann Thorac Cardiovasc Surg 2011; 17: 565-9.

8) Sezai A, Minami K, Hata M, et al. Long-term results (three-year) of emergency coronary artery bypass grafting for patients with unstable angina pectoris. Am J Cardiol 2010; 106: 511-6.

9) Thielmann M, Massoudy P, Neuhaeuser M, et al. Prognostic value of preoperative cardiac troponin I in patients undergoing emergency coronary artery bypass surgery with non-ST-elevation or ST-elevation acute coronary syndromes. Circulation 2006; 114: I448-53.

10) Nishii $M$, Inomata $T$, Takehana $H$, et al. Prognostic utility of B-type natriuretic peptidr assessment in stable low-risk outpatients with nonischemic cardiomyopathy after decompensated heart failure. J Am Coll Cardiol 2008; 51: 2329-35.

11) Sezai A, Shiono M, Orime Y, et al. Low-dose continuous infusion of human atrial natriuretic peptide during and after cardiac surgery. Ann Thorac Surg 2000; 69: 732-8.

12) Sezai A, Hata M, Niino T, et al. Continuous low-dose infusion of human atrial natriuretic peptide in patients with left ventricular dysfunction undergoing coronary artery bypass grafting: the NU-HIT (Nihon University 
working group study of low-dose Human ANP Infusion Therapy during cardiac surgery) for left ventricular dysfunction. J Am Coll Cardiol 2010; 55: 1844-51.

13) Sezai A, Hata M, Niino T, et al. Influence of continuous infusion of low-dose human atrial natriuretic peptide on renal function during cardiac surgery: a randomized controlled study. J Am Coll Cardiol 2009; 54: 1058-64.

14) Sezai A, Hata M, Wakui S, et al. Efficacy of continuous low-dose hANP administration in patients undergoing emergent coronary artery bypass grafting for acute coronary syndrome. Circ J 2007; 71: 1401-07.

15) Sezai A, Hata M, Niino T, et al. Results of low-dose human atrial natriuretic peptide infusion in nondialysis patients with chronic kidney disease undergoing coronary artery bypass grafting: the NU-HIT (Nihon University working group study of low-dose HANP Infusion Therapy during cardiac surgery) trial for CKD. J Am Coll Cardiol 2011; 58: 897-903.

16) Yoshitake I, Sezai A, Hata M, et al. Low-dose atrial natriuretic peptide for chronic kidney disease in coronary surgery. Ann Thorac Cardiovasc Surg 2011; 17: 363-8.

17) Wakui S. Experimental study on myocardial protection by adjunct use of carperitide (hANP) in cardiac surgery. Ann Thorac Cardiovasc Surg 2005; 11: 12-20.

18) Wakui S, Sezai A, Tenderich G, et al. Experimental investigation of direct myocardial protective effect of atrial natriuretic peptide in cardiac surgery.J Thoracic Cardiovasc Surg 2010; 139: 918-25.

19) Mentzer RM, Oz MC, Sladen RN, et al. Effects of perioperative nesiritide in patients with left ventricular dysfunction undergoing cardiac surgery: the NAPA Trial. J Am Coll Cardiol 2007; 49: 716-26.

20) Chen HH, Sundt TM, Cook DJ, et al. Low dose nesiritide and the preservation of renal function in patients with renal dysfunction undergoing cardiopulmonarybypass surgery: a double-blind placebo-controlled pilot study. Ciculation 2007; 116: I134-8.

21) Kitakaze M, Asakura M, Kim J, et al. Human atrial natriuretic peptide and nicorandil as adjuncts to reperfusion treatment for acute myocardial infarction $(\mathrm{J}-$ WIND): two randomized trials. Lancet 2007; 370: 1483-93.

22) Pitt B, Remme W, Zannad F, et al. Eplerenone, a selec- tive aldosterone blocker, in patients with left ventricular dysfunction after myocardial infarction. N Engl J Med 2003; 348: 1309-21.

23) Fraccarollo D, Galuppo P, Hildemann S, et al. Additive improvement of left ventricular remodeling and neurohormonal activation by aldosterone receptor blockade with eplerenone and ACE inhibition in rats with myocardial infarction. J Am Coll Cardiol 2003; 42: 1666 -73.

24) Rutherford JD, Pfeffer MA, Moyé LA, et al. Effects of captopril on ischemic events after myocardial infarction. Results of the Survival and Ventricular Enlargement trial. SAVE investigators. Circulation 1994; 90: 1731-38.

25)Pfeffer MA, McMurray JJ, Velazquez EJ, et al. Valsartan, captopril, or both in myocardial infarction complicated by heart failure, left ventricular dysfunction, or both. N Engl J Med 2003; 349: 1893-906.

26)Dickstein K, Kjekshus J. Effects of losartan and captopril on mortality and morbidity in high-risk patients after acute myocardial infarction: the OPTIMAAL randomised trial. Optimal Trial in Myocardial Infarction with Angiotensin II Antagonist Losartan. Lancet2002; 360: 752-60.

27)Pitt G, Fonarow GC, Gheorghiade M, et al. Improving outcomes in post-acute myocardial infarction heart failure: incorporation of aldosterone blockade into combination therapy to optimize neurohormonal blockade. Am J Cardiol 2006; 97: 26F-33F.

28) Antman EM, Anbe DT, Armstrong PW, et al. ACC/ AHA guidelines for the management of patients with ST-elevation myocardial infarction--executive summary: a report of the American College of Cardiology/ American Heart Association Task Force on Practice Guidelines (Writing Committee to Revise the 1999 Guidelines for the Management of Patients With Acute Myocardial Infarction). Circulation 2004; 110: 588-636.

29) Okainec K, Platt R, Pilote L, et al. Cardiac medical therapy in patients after undergoing coronary artery bypass graft surgery: a review of randomized controlled trials. J Am Coll Cardiol2005; 45: 177-84.

30) Filion KB, Pilote L, Rahme E, et al. Perioperative use of cardiac medical therapy among patients undergoing coronary artery bypass graft surgery: a systematic review Am Heart J 2007; 154: 407-14. 